\title{
Potentiodynamic Studies of Aluminium 2024 Alloy in Different Concentration of Hydrochloric Acid Medium at Laboratory Temperature
}

\author{
Ramya DR and Pruthviraj RD* \\ Department of Chemistry, R\&D Canter, Rajarajeswari college of Engineering, Bengaluru, Karnataka, India \\ *For Correspondence: Pruthviraj RD, Department of Chemistry, R\&D Canter, Rajarajeswari college of Engineering \\ Bengaluru, Karnataka, India, Tel: 9742832678 ; E-mail: pruthvirajrd@gmail.com \\ Received date: Aug 29, 2017, Accepted date: Oct 03, 2017, Published date: Oct 19, 2017 \\ Copyright: 2017 ( ) Ramya DR, et al. This is an open-access article distributed under the terms of the Creative \\ Commons Attribution License, which permits unrestricted use, distribution, and reproduction in any medium, provided \\ the original author and source are credited.
}

\section{Research Article}

\begin{abstract}
Aluminium based alloys are appropriate materials for structural applications in the aircraft and automotive industries. Because they are ductile, highly conductive, high strength to weight ratio and they are heat treatable. The material selected for this research work is Al 2024 alloy which is commercially available. Present paper involves the study of Tafel polarisation and microstructural behaviour of Al 2024. The corrosion studies for Al 2024 were carried out by using electrochemical analyser in various concentration of corrosion medium such as $\mathrm{HCl}$ at laboratory temperature. From microstructural studies, intergranular corrosion with traces of pitting was observed in the samples when immersed in the $\mathrm{HCl}$ solutions. Results indicate that Al 2024 alloy shows more resistance to corrosion.
\end{abstract}

Keywords: Al 2024, Electrochemical analyser, Microstructure, Hydrochloric acid

\section{INTRODUCTION}

Aluminium and its alloys have the wide range of applications in fabrication industry, aircraft manufacturing, automobile industries and other structural applications, due to their high strength to weight ratio, higher ductility and good corrosive resistance. Al 2024 is heat treatable alloy and main alloying element is copper. Mechanical strength of these alloys are increased by addition of copper and magnesium and is added to accelerate the precipitation hardening as well as to achieve benefits from natural aging effects. Al 2024 is extensively used in the aircraft industry for applications such as fuselage skins and frames, and wings due to its high strength to weight ratio and ductility. A broad range of mechanical properties can be achieved in these alloys using different heat treatment and aging combination.

The attractiveness of aluminium is that it is relatively low cost, light weight metal that can be heat treated to high strength levels and it is one of the most easily fabricated of the high performance materials, which usually correlates directly with low costs.

Corrosion, which is an inevitable problem faced by almost all industries can be considered as one of the worst technical calamities of our time. Besides from its direct costs in dollars, corrosion is a serious problem because it definitely contributes to the depletion of our natural resources. Corrosion studies have also become important due to increasing awareness of the need to conserve the world's metal resources ${ }^{[1]}$. Now-a-days more attention is paying to control the metallic corrosion, due to increasing use of metals in many technological fields.

Corrosion studies of aluminium and aluminium alloys have received considerable attention by researchers because of their wide industrial applications and economic considerations ${ }^{[2,3]}$. Aluminium and aluminium alloys have emerged as alternate materials in aero-space and in some chemical processing industries. Due to their wide applications, they frequently come in contact with acids or bases during pickling, de-scaling, electrochemical etching and extensively used in many chemical process industries. Most of the studies were conducted on corrosion of various metals and alloys in $\mathrm{HCl}$ and $\mathrm{H}_{2} \mathrm{SO}_{4}$ media ${ }^{[3-7]}$. 


\section{MATERIAL AND METHOD}

Sample selected for the present research work is commercially available Al 2024 (Table 1).

Table 1. Compositions of Al 2024.

\begin{tabular}{|l|l|l|l|l|l|l|l|l|l|}
\hline Elements & $\mathrm{Cu}$ & $\mathrm{Si}$ & $\mathrm{Mg}$ & $\mathrm{Mn}$ & $\mathrm{Cr}$ & $\mathrm{Zn}$ & $\mathrm{Ti}$ & $\mathrm{Fe}$ \\
\hline$\%$ & 4.38 & 0.05 & 1.5 & 0.5 & 0.01 & 0.02 & 0.06 & 0.12 & $\mathrm{Al}$ \\
\hline
\end{tabular}

\section{Sample Preparation}

Al 2024 samples for electrochemical analysis were prepared with the dimension of $2 \mathrm{~cm} \times 1 \mathrm{~cm}$. The surface of the samples are thoroughly polished by different grade of emery papers. After getting smooth surface, samples should wash with distilled water and then with acetone and allowed to dry in air for further use ${ }^{[8,9]}$.

\section{Solution Preparation}

Solutions of hydrochloric acid medium was prepared by using analytical grade hydrochloric acid and double distilled water. It was standardized by potentiometric method. Hydrochloric acid of concentrations $1 \mathrm{~N}, 0.75 \mathrm{~N}, 0.5 \mathrm{~N}, 0.25 \mathrm{~N}$ were prepared by appropriate dilution ${ }^{[10-13]}$.

\section{Experimental Procedure for Tafel Polarization}

Electrochemical measurements were carried out by using an electrochemical work station, CH600D-series, U.S. Model with $\mathrm{CH}$ instrument beta software. The electrochemical cell used was a conventional three-electrode compartment having glass cell with a platinum counter electrode and a saturated calomel electrode (SCE) as reference. The working electrode was made up of Al 2024. All the values of potential were measured with reference to the saturated calomel electrode [14-18]

\section{Tafel Polarization Studies}

Finely polished Al 2024 alloy specimens with $1.0 \mathrm{~cm}^{2}$ surface area were exposed to corrosion medium of different concentrations of hydrochloric acid $(1 \mathrm{~N}, 0.75 \mathrm{~N}, 0.5 \mathrm{~N}$ and $0.25 \mathrm{~N})$ separately at a laboratory temperature [19,20]. The potentiodynamic current-potential curves were recorded by polarizing the specimen to $-250 \mathrm{mV}$ cathodically and +250 $\mathrm{mV}$ anodically with respect to open circuit potential (OCP) at a scan rate of $0.01 \mathrm{~V} / \mathrm{s}$ (Figures 1-5).

\section{Microstructural Analyses of the Samples}

The effects of heat treatment on the microstructures of the samples were studied using the SEM analysis (Figures 6 and 7). It was observed that the morphologies of the Al 2024 samples changed with the increase in concentration of $\mathrm{HCl}$ solution. Some grains are noticed within structures of the samples as the austenitic concentration increased. This significantly alters the orientation of the grains in these samples and it was expected that this change will affect the corrosion behaviour of these samples when immersed in the acidic medium [21-24]. The SEM images of the control sample Al 2024 before immersion was observed and presented in Figure 6 . The grain boundaries are even hardly visible due to homogeneity of the constituents in the material [25]. The SEM image of the Al 2024 sample when immersed in different concentration of the $\mathrm{HCl}$ solution is shown in the Figure 7. This figure reveals visible phases present in the Al 2024 and cracks are clearly visible along the grain boundaries of the sample. This is an indication that the heat treat this sample was subjected to, has created some internal stresses which have caused cracks within the phases of the material ${ }^{[26-28]}$.

\section{RESULT AND DISCUSSION}

The effect of hydrochloric acid medium on the corrosion rate of Al 2024 alloy was studied using Tafel polarization technique. Figures 1-5 represent the potentiodynamic polarization curves of 2024 aluminium alloy in different concentration of $\mathrm{HCl}$ medium at lab temperature. Corrosion parameters such as corrosion potential (Ecorr), corrosion current density (icorro) anodic slope and cathodic slope are obtained from Tafel polarisation curves. Results are tabulated in tables. The corrosion rate directly obtained from $\mathrm{CH}$ software (Table 2). The result indicate the decrease in the corrosion rate with an decrease in the concentration of $\mathrm{HCl}$ medium [29]. 


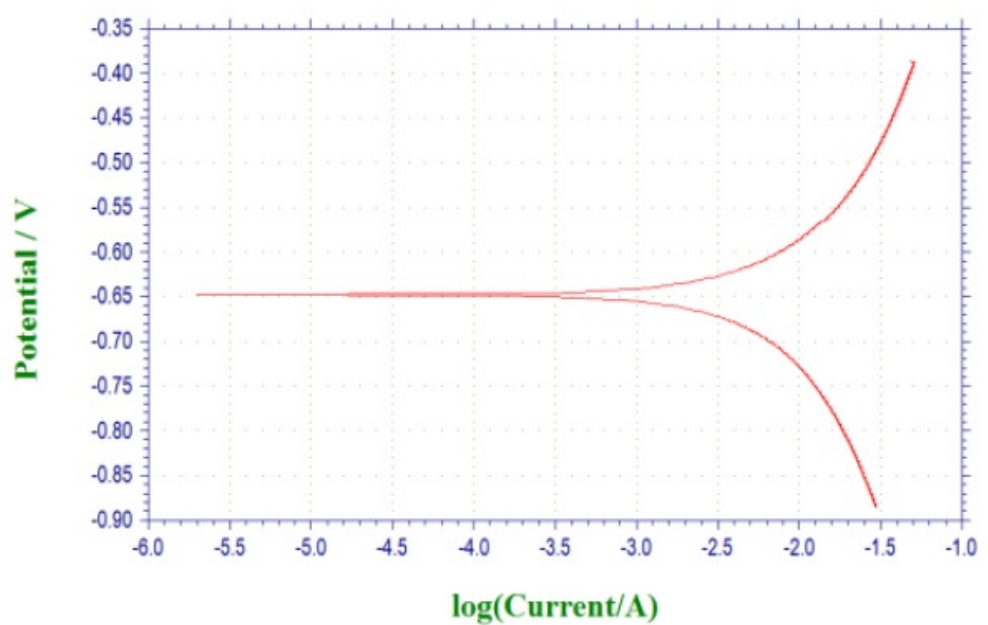

Figure 1. Tafel polarization curve in $1 \mathrm{~N} \mathrm{HCl}$.

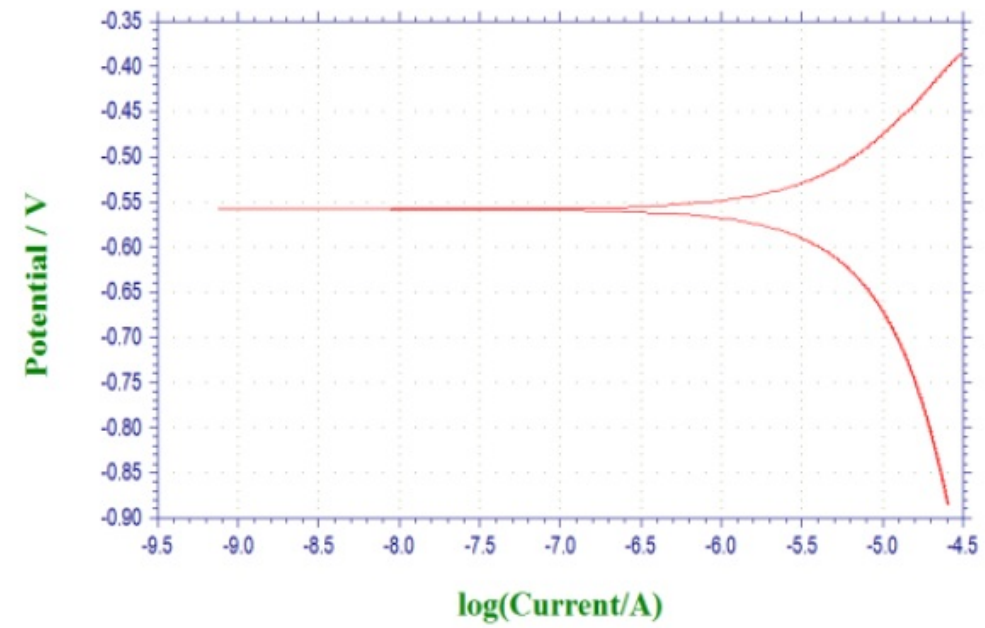

Figure 2. Tafel polarization curve in $0.75 \mathrm{~N} \mathrm{HCl}$.

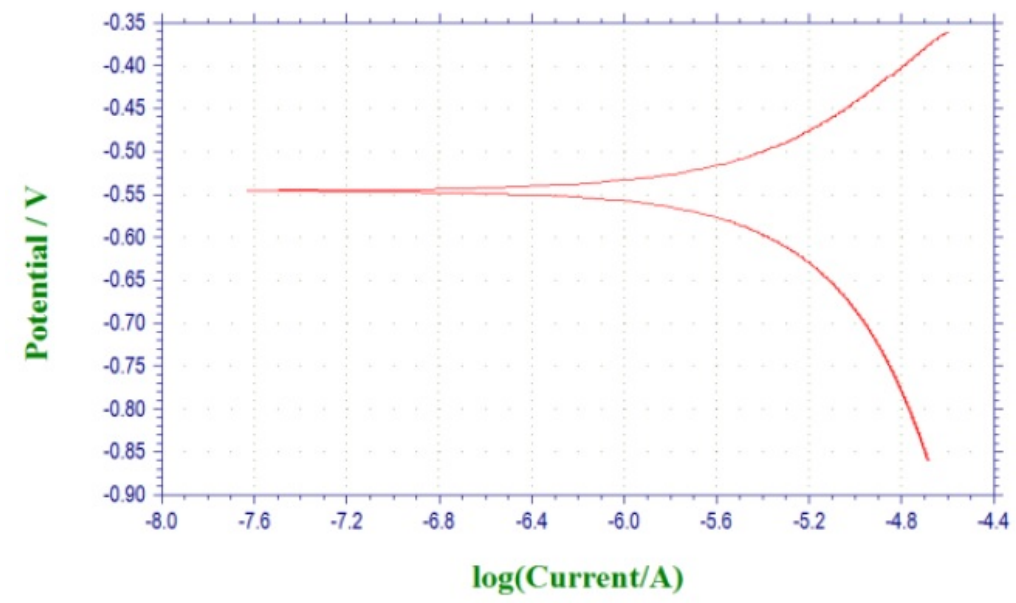

Figure 3. Tafel polarization curve in $1 \mathrm{~N} \mathrm{HCl}$. 


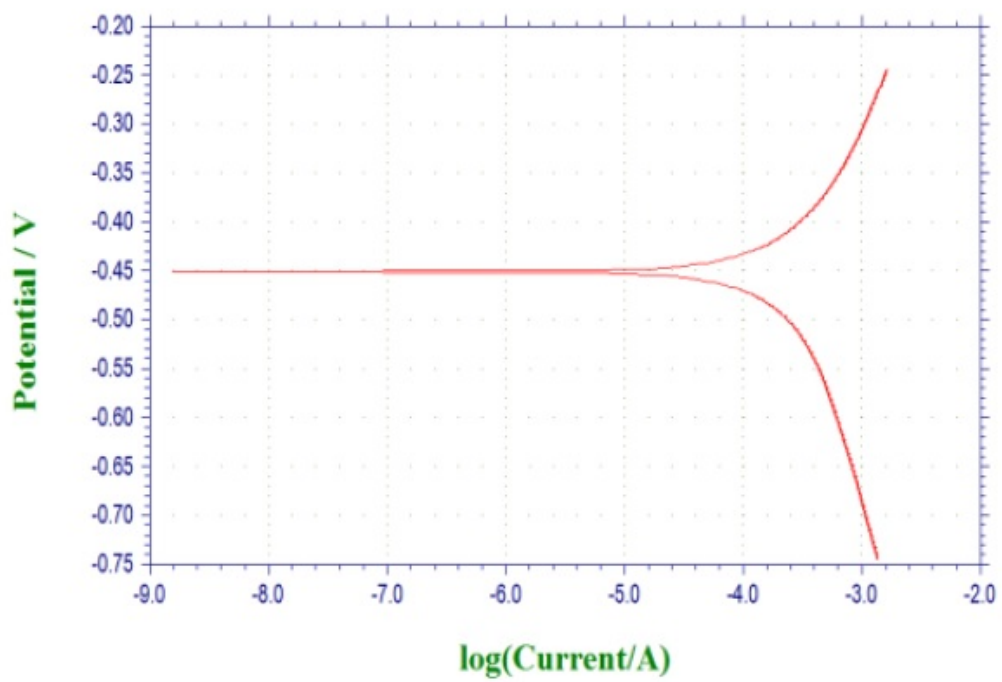

Figure 4. Tafel polarization curve in $0.75 \mathrm{~N} \mathrm{HCl}$.

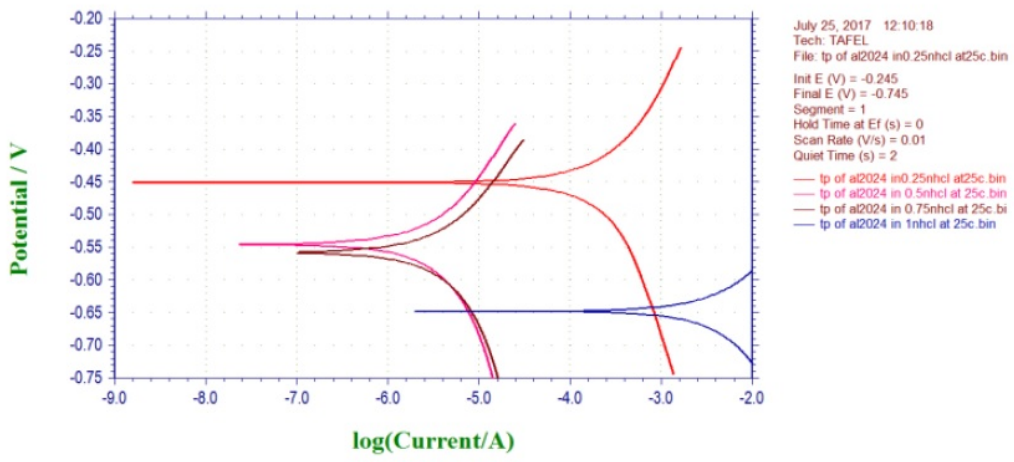

Figure 5. Combined Tafel polarization curve in different concentration of $\mathrm{HCl}$ solution.

Table 2. Results of Tafel polarization studies of 2024 aluminium alloy in $\mathrm{HCl}$ medium.

\begin{tabular}{|l|l|l|l|}
\hline Concentration of $\mathrm{HCl}(\mathrm{N})$ & $\mathrm{E}_{\text {corro }}(\mathrm{V})$ & $\mathrm{i}_{\text {corro }}(\mathrm{A})$ & Corrosion rate $(\mathrm{mpy})$ \\
\hline 0.25 & -0.633 & $2.358 \times 10^{-5}$ & 9.6 \\
\hline 0.5 & -0.665 & $3.356 \times 10^{-5}$ & 13.8 \\
\hline 0.75 & -0.692 & $4.155 \times 10^{-4}$ & 170.4 \\
\hline 1 & -0.712 & $5.762 \times 10^{-3}$ & 2363 \\
\hline
\end{tabular}

The SEM images of freshly polished surface of Al 2024 alloy given in the Figure 6, which shows polished surface with few scratches due to polishing. The surface morphology of Al 2024 alloy sample was examined by SEM, immediately after corrosion test in $1 \mathrm{~N}, 0.75 \mathrm{~N}, 0.5 \mathrm{~N}, 0.25 \mathrm{~N} \mathrm{HCl}$ medium. The SEM images of corroded sample given in Figure 7 shows that the degradation of alloy with more or less uniform attack of $\mathrm{HCl}$ medium. Figure 8 represent X-Ray Diffraction spectrum of polished sample of Al 2024 alloy. The spectrum shows peeks for aluminium and oxygen suggesting the presence of aluminium oxide hydroxide ${ }^{[30-32] .}$

Aluminium and its alloy have air formed oxide film of aluminium hydroxide in acid solution. The mechanism of dissolution of aluminium is as follows:

$\mathrm{Al}+\mathrm{H}_{2} \mathrm{O} \rightarrow \mathrm{AlOH}^{-}+\mathrm{H}^{+}+\mathrm{e}^{-}$ 


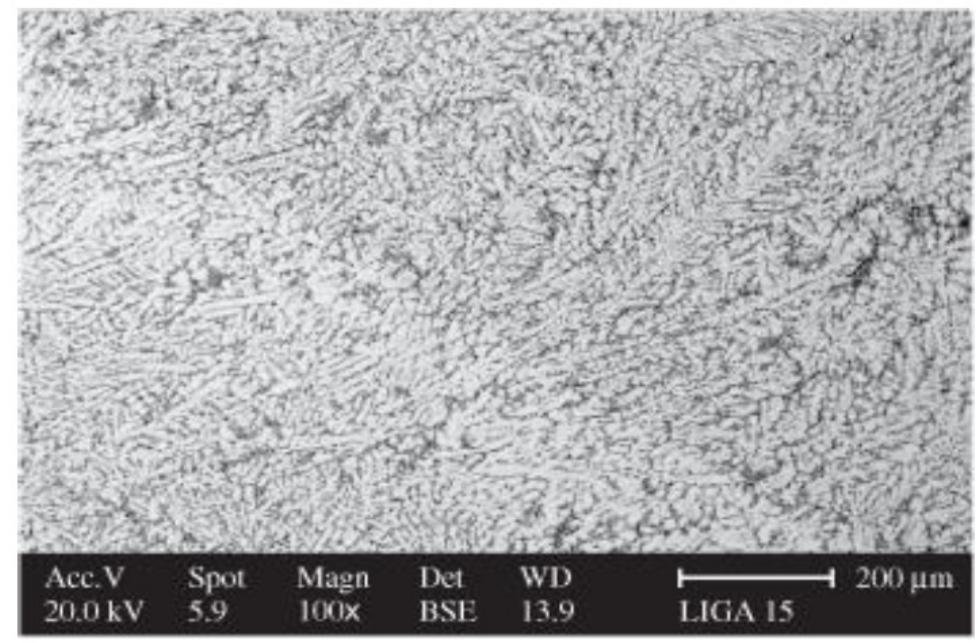

Figure 6. Al 2024 alloy before corrosion test.
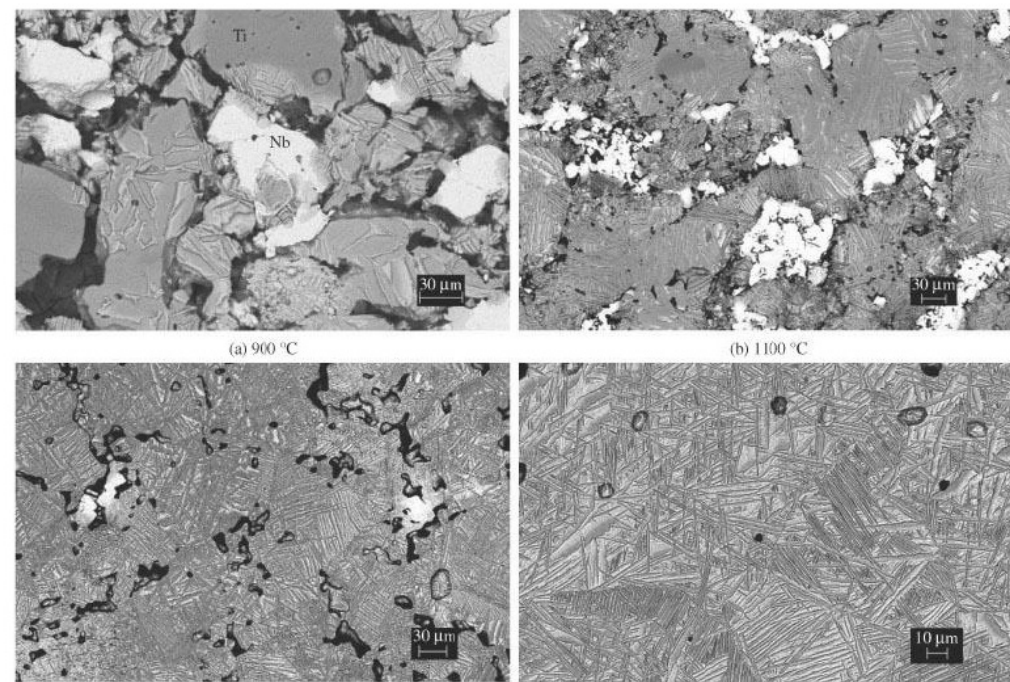

(b) $1100^{\circ} \mathrm{C}$

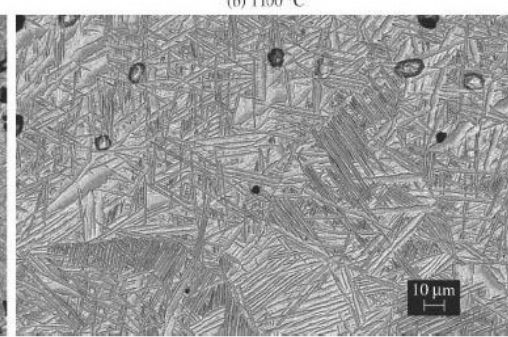

Figure 7. SEM images of corroded surface of Al 2024 in $1 \mathrm{~N}, 0.75 \mathrm{~N}, 0.5 \mathrm{~N}, 0.25 \mathrm{~N}$, Hydrochloric acid solutions.

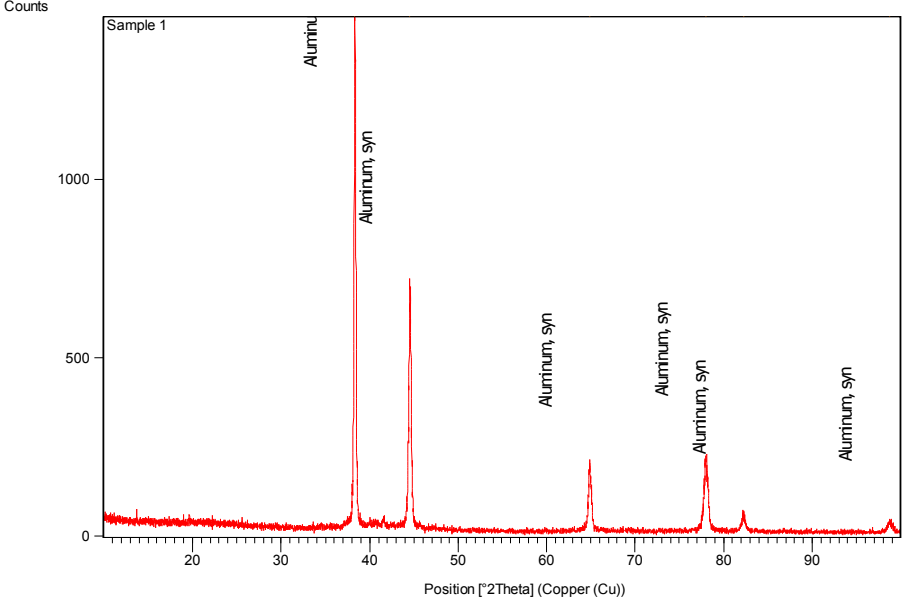

Figure 8. X-ray diffraction pattern Spectrum of Al 2024 alloy. 


\section{CONCLUSION}

The corrosion behaviour of Aluminium 2024 alloy in different concentrations of $\mathrm{HCl}$ solutions was investigated by potentiodynamic technique. Aluminium 2024 alloy undergoes corrosion in $\mathrm{HCl}$ medium which shows corrosion rate decreases with decrease in the concentration of $\mathrm{HCl}$ solution. Corrosion current increases with increase in concentration of hydrochloric acid. SEM images shows that as the concentration of $\mathrm{HCl}$ solution increases, formation of pits on the $\mathrm{Al}$ 2024 sample also increases.

\section{ACKNOWLEDGEMENT}

Authors sincerely thank to Vision group on science and Technology (VGST/CISEE/GRD-325), Government of Karnataka for funding this research work and also thank to Management and Principal of RajaRajeswari College of Engineering for providing infrastructural facility to complete this research work.

\section{REFERENCES}

1. Stansbury EE and Buchanan RA. Fundamentals of Electro-chemical Corrosion. ASM Int Mater Park, USA 2000.

2. Badaway WA, et al. Electro chemical behavior and corrosion inhibition of Al, Al-6061 and Al-Cu inneutral aqueous solutions. Corros. Sci 1999;41:709-727.

3. Paul Sigwalt and Juniere M. Aluminium in the Chemistry and Food Industries. British Aluminium Co. Ltd., London 1964;46.

4. Ating El, et al. Leaves extract of Ananas sativumas green corrosion inhibitor for aluminium in hydrochloric acid solutions. Green Chem Lett Rev 2008;3:61-68.

5. Umoren SA, et al. The Inhibition of aluminum corrosion in hydrochloric acid solution by exudate gum from Raphia hookeri. Desalination 2009;247:561-572.

6. Obi-Egbedi NO, et al. SpondiasmombinL. as a green corrosion inhibitor for aluminium in sulphuric acid:Correlation between inhibitive effect and electronic properties ofextracts major constituents using density functional theory. Arabian J Chem 2012;5:361-373.

7. Nnanna LA, et al. Comparative study of corrosion inhibition of aluminium alloy of type AA3003 in acidic and alkaline media by Euphorbia hirta extract. Afr J Pure Appl Chem 2011;5:265-271.

8. Abdel-Gaber AM, et al. Inhibition of aluminum corrosion in alkaline solutions usingnatural compound. Mater Chem Phys 2008;109:297-305.

9. Deepa, et al. Coriandrum sativum L. - a novel green inhibitor for the corrosion inhibition of aluminium in $1.0 \mathrm{M}$ phosphoric acid solution. J Environ Chem Eng 2013;1:676-683.

10. Deepa, et al. Corrosion Behaviour of 6063 aluminium alloy in acidic and alkaline media. Arabian J Chem 2013;1-12.

11. El-Neami KKH. Inhibition of the corrosion of iron by oxygen and nitrogen containing compounds. Monatsh Chem J 1995;126:369-376.

12. El-Sayed A. Phenothiazine as inhibitor of the corrosion of cadmium in acidic solutions. J Appl Electrochem 1997;27:193-200.

13. El-Neami KKH. Inhibition of the corrosion of iron by oxygen and nitrogen containing compounds. Monatsh. Chem J 1995;126:369-376.

14. El-Sayed A. Phenothiazine as inhibitor of the corrosion of cadmium in acidic solutions. J Appl Electrochem 1997;27:193-200.

15. Moon SM and Pyun SI 1998. Growth mechanism of anodic oxidefilms on pure aluminium in aqueous acidic and alkaline solutions. J Solid State Electrochem 1991;2:156-161.

16. Moon SM and Pyun SI. The formation and dissolution of anodic oxide films on pure aluminium in alkaline solution. Electrochim Acta 1995;44:2445-2454.

17. Morad MS. Influence of propargyl alcohol on the corrosionbehaviour of mild steel in $\mathrm{H}_{3} \mathrm{PO}_{4}$ solutions. Mater $\mathrm{Chem}$ Phys 1990;60:188-195.

18. Obot IB, et al. Synergistic and antagonistic effects of anions and Ipomoea invulc-rata as green corrosion inhibitor for aluminium dissolution inacidic medium. Int J Electrochem Sci 2010;5:994-1007. 
19. Oguzie EE. Corrosion inhibition of aluminum in acidic andalkaline media by Sansevieria trisfasciata extract. Corros Sci 2007;49:1527-1539.

20. Poornima T, et al. Corrosion of aged andannealed $18 \mathrm{Ni} 250$ grade maraging steel in phosphoric acidmedium. Int J Electrochem Sci 2010;5:56-71.

21. Wernick S. The Surface Treatment and Finishing of Aluminum and its Alloys. ASM International, Ohio 1987;1:935.

22. Wit JH and Lenderink HJW. Electrochemical impedance spectroscopy as a tool to obtain mechanistic information on the passive behaviour of aluminium. Electrochim Acta 1996;41:1111-1119.

23. Trowsdale AJ. The influence of silicon carbide rein-forcement on the pitting behaviour of aluminium. Corros Sci 1996;2:177-191.

24. Soltis J. Passivity breakdown, pit initiation and propagation of pits in metallic materials-review. Corros Sci 2015;90:5-22.

25. ASTM G1-03. Standard Practice for Preparing, Cleaning, and Evaluating Corrosion Test Specimens. ASTM International, USA 2011.

26. ASTM G59-97. Standard Test Method for Conducting Potentiodynamic Polarization Resistance Measurements. USA 2014.

27. ASTM G102-89. Standard Practice for Calculation of Corrosion Rates and Related Information from Electrochemical Measurements. USA 2015 e1.

28. Y Choi, et al. Effect of $\mathrm{H}_{2} \mathrm{~S}$ on the $\mathrm{CO}_{2}$ corrosion of carbon steel in acidic solutions. Electrochim. Acta 56 2011;1752-1760.

29. ASTM NACE/ASTMG31-12a. Standard Guide for Laboratory Immersion Corrosion Testing of Metals. USA 2012.

30. Winstone Revie R. Kruger Uhlig's Corrosion Handbook (3 $3^{\text {rd }}$ edn.), Wiley, New Jersey, USA 2011.

31. Fredriksson W, et al. Full depth profile of passive films on 316L stainless steel based on high resolution HAXPES in combination with ARXPS. Appl Surf Sci 2012;258:5790-5797.

32. Ahmad K. Principles of Corrosion Engineering and Corrosion Control (Butterworth-Heinemann, Oxford, 2006. 